\title{
ISOLATED PARALYSIS OF THE INFRASPINATUS MUSCLE
}

\author{
KENJI TAKAGISHI, AKIHIKO SAITOH, MASATOSHI TONEGAWA, TOSHIAKI IKEDA, MORITOSHI ITOMAN
}

From Kitasato University, Japan

We report six patients with isolated paralysis of the infraspinatus and discuss the diagnosis, pathology, treatment, and outcome over a mean follow-up period of 33 months.

Four patients were shown to have space-occupying lesions at the spinoglenoid notch by MRI or ultrasonography or both, and ganglia were confirmed and removed surgically in three, with good results. Ganglia at this site are not uncommon and should be included in the differential diagnosis of patients presenting with shoulder pain and weakness.

J Bone Joint Surg [Br] 1994; 76-B:584-7.

Received 15 March 1994; Accepted 6 April 1994

Isolated paralysis of the infraspinatus muscle is rarely considered in the differential diagnosis of pain in the shoulder although several cases have been reported (Ganzhorn et al 1981; Thompson, Schneider and Kennedy 1982; Ferretti, Guglielmo and Russo 1987; Black and Lombardo 1990; Ogino et al 1991).

We have already described one patient with infraspinatus paralysis due to a ganglion in the spinoglenoid notch (Takagishi et al 1991) and we now report a further three cases.

\section{PATIENTS}

From 1987 to 1991 , a total of 1540 patients were referred to the first author for shoulder pain. In six of them, the diagnosis of isolated paralysis of the infraspinatus muscle was made from a combination of clinical and EMG findings after other diseases had been excluded.

The patients were all male and aged from 17 to 42 years (mean 32) (Table I), and five had been keen sportsmen for at least five years. In one, palsy developed

K. Takagishi, MD, Associate Professor of Orthopaedic Surgery

A. Saitoh, MD, Orthopaedic Surgeon

M. Tonegawa, MD, Orthopaedic Surgeon

T. Ikeda, MD, Radiologist

M. Itoman, MD, Professor of Orthopaedic Surgery

Kitasato University School of Medicine, 1-15-1 Kitasato, Sagamihara,

Kanagawa 228, Japan.

Correspondence should be sent to Dr K. Takagishi.

(C)1994 British Editorial Society of Bone and Joint Surgery $0301-620 \mathrm{X} / 94 / 4853 \$ 2.00$ after arthroscopy and manipulation for a frozen shoulder. Review was from two to four years after surgery or the start of conservative treatment (mean 2 years 9 months); five were examined and one was interviewed by telephone.

\section{RESULTS}

All six patients had pain or aching in the shoulder and four complained of weakness.

Examination revealed atrophy of the infraspinatus muscle and weakness of external rotation and abduction in all cases. Four patients with tenderness over the spinoglenoid notch were all later found to have spaceoccupying lesions. One had tenderness in the middle of the infraspinatus fossa after failed arthroscopy and manipulation for frozen shoulder.

Investigations included EMG, ultrasonography, MRI, and arthrography (Table I) and EMG showed isolated paralysis of the infraspinatus muscle in all six. Radiographs showed no marked abnormalities but ultrasound revealed homogeneous hypoechogenic areas near the base of the scapular spine in four patients (Fig. 1) and only atrophy of the infraspinatus and no rotator-cuff tear in two. MRI showed well-defined areas of increased signal intensity over the spinoglenoid notch of the scapula in T2-weighted or fast-scan images in three (Figs 2 and 3). Arthrography in four cases showed no positive findings.

Three of the patients with cystic space-occupying lesions had operations after at least three months of conservative treatment (Table II). Through a posterior approach, a ganglion arising from the posterior capsule of the shoulder was found to be compressing the inferior branch of the suprascapular nerve in all (Fig. 4). The ganglia were removed with care to preserve the nerves, and the histological findings were consistent with a ganglion cyst in all.

They all recovered uneventfully, and repeated EMG showed reinnervation at 5 to 11 months after operation. At latest review all had pain relief and full activity. Muscle atrophy had recovered in two of the three.

The fourth patient with a cystic lesion was managed conservatively, and reported by telephone that he had regained full activity without pain two years after diagnosis.

The patient with severe scapular pain after failed arthroscopy and manipulation was treated with analgesics. An EMG seven weeks later showed acute denervation of 


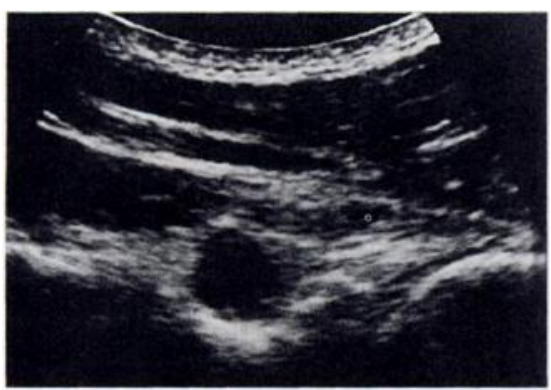

Fig. 1a

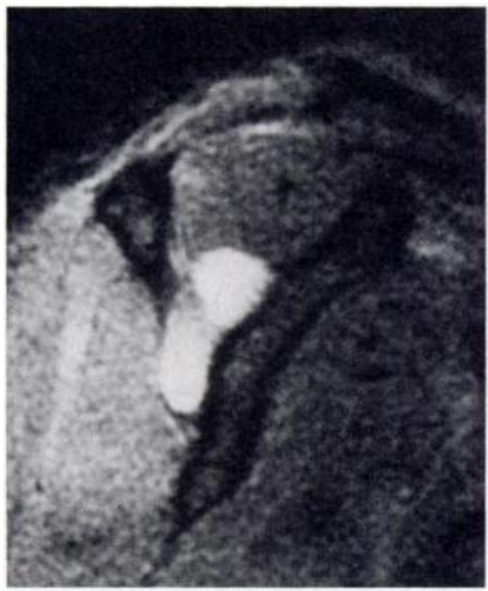

Fig. 2a

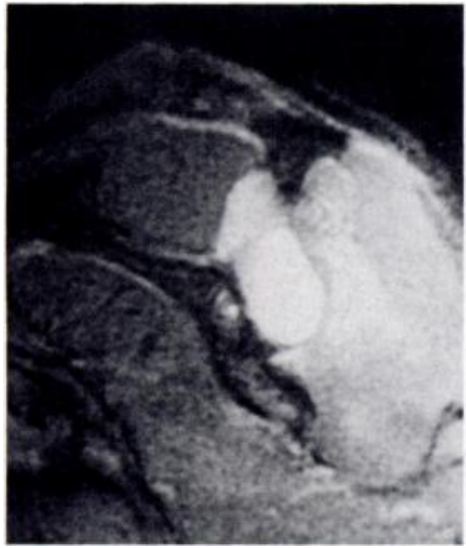

Fig. 3a

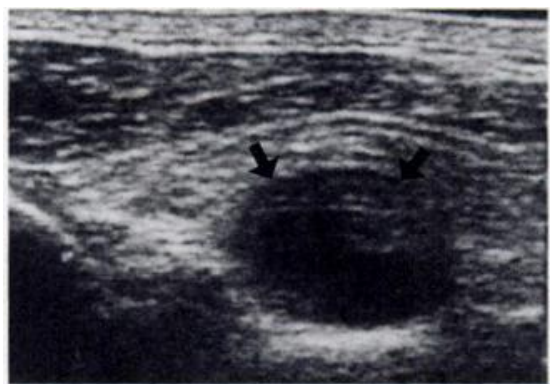

Fig. 1b

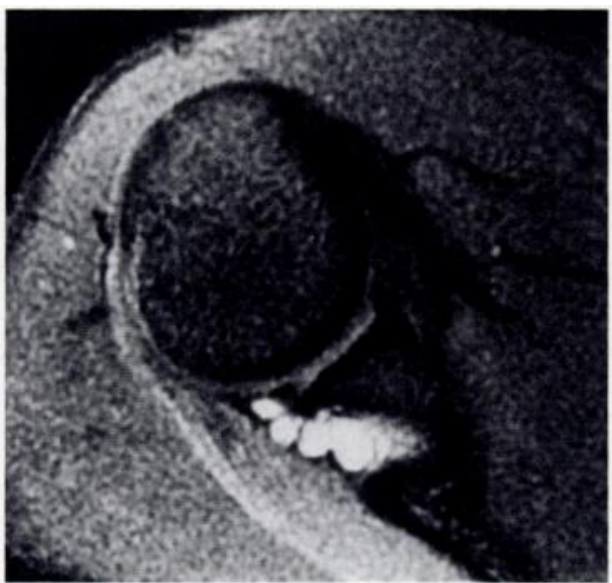

Fig. 2b

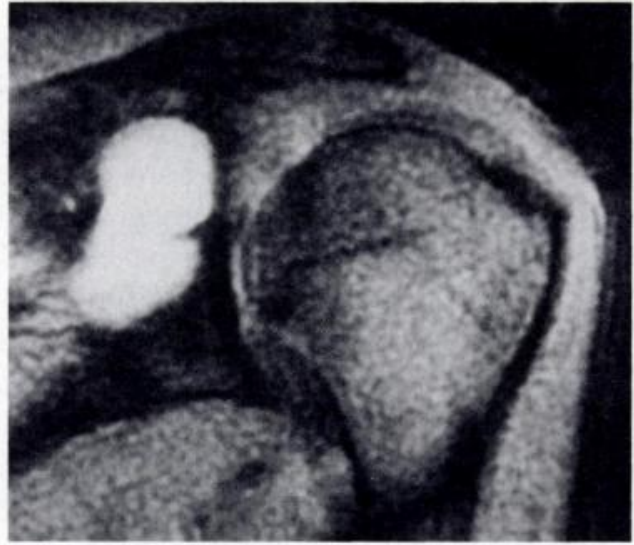

Fig. $3 b$
Ultrasonograms showing cystic lesions below the spine of the scapula in case 2(a) and case 3(b).
Fast-scan MRI in case 2. Ganglion cysts are seen at the spinoglenoid notch on images in the sagittal oblique plane (a) and the horizontal plane (b).
Fast-scan MRI in case 3, showing the sagittal oblique plane (a) and the scapular plane (b).

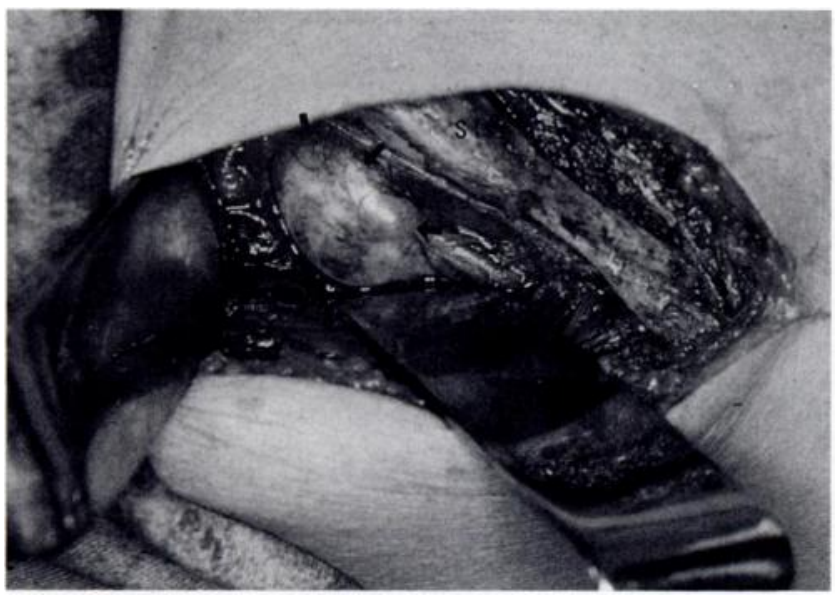

Fig. 4

Case 3. Operative photograph showing large ganglionic cysts (arrows) at the lateral border of the spine of the scapula (S; spine of the scapula). 
Table I. Details of six patients with isolated paralysis of the infraspinatus and the outcome

\begin{tabular}{llllllll}
\hline Case & $\begin{array}{c}\text { Age } \\
\text { (yr) }\end{array}$ & Sex & Comments/complications & $\begin{array}{l}\text { Involved/dominant } \\
\text { side }\end{array}$ & Investigations & & \\
\cline { 6 - 7 } & 26 & M & Baseball player & R/R & Space-occupying lesion & Space-occupying lesion & Normal \\
2 & 25 & M & Body-builder & R/L & Space-occupying lesion & Space-occupying lesion & Normal \\
3 & 40 & M & - & L/L & Space-occupying lesion & Space-occupying lesion & Normal \\
4 & 40 & M & Tennis player & R/R & Space-occupying lesion & - & - \\
5 & 42 & M & Failed arthroscopy and MUA & R/R & Infraspinatus atrophy & Normal & Normal \\
6 & 17 & M & Volley-ball player & R/R & Infraspinatus atrophy & Normal & - \\
\hline
\end{tabular}

the infraspinatus only, with delayed motor-nerve conduction time. His pain gradually subsided and EMG showed evidence of reinnervation five months later. One other patient, a senior high-school volley-ball player with no cystic lesion, showed reinnervation of the infraspinatus on EMG at five months and returned to volley-ball after ten months.

\section{DISCUSSION}

The suprascapular nerve arises from the upper trunk of the brachial plexus, passes through the suprascapular foramen, and supplies the supraspinatus muscle and articular branches to the shoulder and acromioclavicular joint. The nerve then courses laterally and inferiorly around the spinoglenoid notch to innervate the infraspinatus.

Isolated paralysis of the infraspinatus is considered to be rare. It may result from fractures of the scapula, injury at the spinoglenoid notch due to repeated overhead throwing during sport (Ferretti et al 1987), or to a tumour causing pressure (Ganzhorn et al 1981; Thompson et al 1982; Ogino et al 1991; Takagishi et al 1991). In our series, half the cases were caused by ganglia, and other reports suggest that isolated paralysis of the infraspinatus muscle due to ganglia is not as rare as previously suspected (Fritz et al 1992).

All our patients had shoulder pain, wasting of the infraspinatus but not the supraspinatus, and weakness of external rotation and abduction. EMG appears to be the definitive test for entrapment of the suprascapular nerve and we were able to demonstrate isolated paralysis of its inferior branch.

The differentiation between patients with rotatorcuff tears and those with suprascapular nerve lesions may be difficult (Drez 1976), but EMG and arthrography may help. These tests do not show the exact cause of suprascapular nerve entrapment, but MRI and ultrasound give more information on both diagnoses (Middleton et al 1986; Iannotti et al 1991). Four of our six patients had space-occupying lesions in the spinoglenoid notch, and no abnormality of the rotator cuff. These last investigations gave the exact diagnosis of a ganglion causing isolated
Table II. Results of treatment

\begin{tabular}{llll}
\hline Case & Treatment & $\begin{array}{l}\text { Follow-up } \\
(\mathbf{y r})\end{array}$ & EMG result \\
\hline 1 & Removal of ganglia & 4 & Reinnervation at 5 months \\
2 & Removal of ganglia & 3 & Reinnervation at 11 months \\
3 & Removal of ganglia & 2.5 & Reinnervation at 3 months \\
4 & Conservative & 2 & - \\
5 & Conservative & 2.4 & $\begin{array}{l}\text { Reinnervation } 5 \text { months } \\
\text { after diagnosis }\end{array}$ \\
6 & Conservative & 3 & Reinnervation at 9 months \\
\hline
\end{tabular}

paralysis of the infraspinatus muscle, as well as excluding rotator-cuff tear. All patients with space-occupying lesions at the base of the scapular spine had tenderness over the spinoglenoid notch inferiorly and this may be a helpful clinical finding.

In our patient with acute denervation seven weeks after failed arthroscopy, the shoulder manipulation itself may have caused the paralysis. Birch, Jessop and Scott (1991) described brachial plexus palsy after manipulation for a frozen shoulder; damage limited to the inferior branch of the suprascapular nerve has not been reported previously. It seems probable that the tip of a blunt trochar slipped posteriorly during repeated attempts to enter the joint and injured the nerve. The volley-ball player with reversible palsy probably suffered repeated stretching of the nerve during the follow-through of the arm when serving (Ferretti et al 1987).

Treatment of isolated paralysis of the infraspinatus depends on the duration of symptoms, the location of any entrapment, and the aetiology. We advise that paralysis of acute onset be managed by analgesics and rest, but three of the four patients with space-occupying lesions at the spinoglenoid notch subsequently required the removal of ganglia. Our results after operation are uniformly good, but the nerve must be carefully preserved.

Conclusions. Isolated paralysis of the infraspinatus due to ganglia is not as uncommon as thought previously. MRI and ultrasound can determine the diagnosis and location of any ganglion and also assess the status of the 
rotator cuff. These investigations are advised for the differential diagnosis of patients with shoulder pain and muscle weakness.

No benefits in any form have been received or will be received from a commercial party related directly or indirectly to the subject of this article.

\section{REFERENCES}

Birch R, Jessop J, Scott G. Brachial plexus palsy after manipulation of the shoulder. J Bone Joint Surg [Br] 1991; 73-B:172.

Black KP, Lombardo JA. Suprascapular nerve injuries with isolated paralysis of the infraspinatus. Am J Sports Med 1990; 18:225-8.

Drez DJ Jr. Suprascapular neuropathy in the differential diagnosis of rotator cuff injuries. Am J Sports Med 1976; 4:43-5.

Ferretti A, Guglielmo C, Russo G. Suprascapular neuropathy in volleyball players. J Bone Joint Surg [Am] 1987; 69-A:260-3.
Fritz RC, Helms CA, Steinbach LS, Genant HK. Suprascapular nerve entrapment: evaluation with MR imaging. Radiology 1992; 182: 437-44.

Ganzhorn R, Hocker JT, Horowitz M, Switzer HE. Suprascapular-nerve entrapment: a case report. J Bone Joint Surg [Am] 1981; 63-A:492-4.

Iannotti JP, Zlatkin MB, Esterhai JL, et al. Magnetic resonance imaging of the shoulder: sensitivity, specificity, and predictive value. J Bone Joint Surg [Am] 1991; 73-A:17-29.

Middleton WD, Reinus WR, Totty WG, et al. Ultrasonographic evaluation of the rotator cuff and biceps tendon. J Bone Joint Surg [Am] 1986; 68-A:440-50.

Ogino T, Minami A, Kato $\mathbf{H}$, et al. Entrapment neuropathy of the suprascapular nerve by a ganglion: a report of three cases. $J$ Bone Joint Surg [Am] 1991; 73-A:141-7.

Takagishi K, Maeda K, Ikeda T, Itoman M, Yamamoto M. Ganglion causing paralysis of the suprascapular nerve: diagnosis by MRI and ultrasonography. Acta Orthop Scand 1991; 62:391-3.

Thompson RC, Schneider W, Kennedy T. Entrapment neuropathy of the inferior branch of the suprascapular nerve by ganglia. Clin Orthop $1982 ; 166: 185-7$. 